\title{
Pediatric falls from windows and balconies: incidents and risk factors as reported by newspapers in the United Arab Emirates
}

\author{
Michal Grivna ${ }^{1 *}$, Hanan M. Al-Marzouqi ${ }^{2}$, Maryam R. Al-Ali ${ }^{2}$, Nada N. Al-Saadi ${ }^{2}$ and Fikri M. Abu-Zidan ${ }^{3}$
}

\begin{abstract}
Background: Falls of children from heights (balconies and windows) usually result in severe injuries and death. Details on child falls from heights in the United Arab Emirates (UAE) are not easily accessible. Our aim was to assess the incidents, personal, and environmental risk factors for pediatric falls from windows/balconies using newspaper clippings.

Methods: We used a retrospective study design to electronically assess all major UAE national Arabic and English newspapers for reports of unintentional child falls from windows and balconies during 2005-2016. A structured data collection form was developed to collect information. Data were entered into an Excel sheet and descriptive analysis was performed.

Results: Newspaper clippings documented 96 fall incidents. After cleaning the data and excluding duplicate cases and intentional injuries, 81 cases were included into the final analysis. Fifty-three percent $(n=42)$ were boys. The mean (range) age was 4.9 years (1-15). Thirty-eight (47\%) children fell from windows and 36 (44\%) from balconies. Twenty-two (27\%) children climbed on the furniture placed on a balcony or close to a window. Twenty-five (31\%) children were not alone in the apartment when they fell. Twenty-nine children fell from less than 5 floors (37\%), 33 from 5 to 10 floors (42\%) and 16 from more than 10 floors (21\%). Fifteen children (19\%) were hospitalized and survived the fall incident, while 66 died (81\%).
\end{abstract}

Conclusions: Newspapers proved to be useful to study pediatric falls from heights. It is necessary to improve window safety by installing window guards and raising awareness.

Keywords: Falls from windows, Balconies, Children, UAE

\section{Background}

Unintentional falls are the second leading cause of injuryrelated hospitalization for all ages accounting for about 30\% of injury admissions and 15\% of all Emergency Department visits [1, 2]. Falls of children from heights (balconies and windows) often result in severe injuries and death [3]. These falls were described in a chapter called "Falling out of a window" in "The Book of Accidents" 1830. The authors stressed the importance of supervision and vigilance of parents and maids [4]. Community education and installation of window guards, starting in 1970s in several US cities, led

\footnotetext{
* Correspondence: m.grivna@uaeu.ac.ae

${ }^{1}$ Institute of Public Health, College of Medicine and Health Sciences, UAE

University, Al-Ain, United Arab Emirates

Full list of author information is available at the end of the article
}

to successful decrease of these injuries [3]. The famous intervention "Children Cannot Fly" targeting parents with extensive educational campaign and distribution of free window guards in New York City in 1976 resulted in 96\% reduction of unintentional window falls $[5,6]$.

United Arab Emirates is a Middle-East country with a fast economic development characterized by diversification from the oil industry to other sectors, as tourism, retail and manufacturing. The population of the UAE increased rapidly and recently reached over 9 million inhabitants, of whom less than $18 \%$ are UAE Nationals [7]. Children less than 15 years old constitute about $20 \%$ of the population [7]. The country is a federation of seven emirates (Abu Dhabi, Ajman, Dubai, Fujairah, Ras Al Khaimah, Sharjah, and Umm al-Quwain). 
Despite improvements in the health care, injuries remain a leading cause of morbidity and mortality in the UAE, especially among children and youth [8]. The injury death rate for children under 15 years old was 13.6 per 100.000 person-years during 2000-2008 [8]. Various ethnic groups with diverse socio-cultural, religious and educational background pose a special challenge for safety promotion in the UAE [8].

Details on child falls from heights in the United Arab Emirates (UAE) are not easily accessible. Our aim was to assess the incidents, activities and risk factors for pediatric falls from windows/balconies in the UAE using newspaper clippings.

\section{Methods}

We used a retrospective survey to assess eight UAE national Arabic and English newspapers for reports on unintentional child falls from heights (windows, balconies) at residential buildings during 2005-2016. Children 015 years were included. Intentional injuries, as suicide, homicide, and from other buildings (school, hotel) were excluded. We searched newspapers electronically using key words including child/boy/girl/baby/toddler and fall/ fell/died and window/balcony/height. A structured data collection form was designed.

Variables collected included demography, location of injury (Emirate), supervision of a child, equipment (furniture), environmental factors (balcony or window, number of floors) and outcome (died on spot, died in the hospital, survived). Nationality was divided into four categories (UAE national, Asian, other Arabs, and others). Four investigators did the search independently checking for completeness of reporting. Data of fall incidents were entered into an Excel sheet. Descriptive analysis was performed. Official letters were written to health authorities
(Ministry of Health, Health Authority Abu Dhabi, Dubai Health Authority) in order to obtain mortality and morbidity reports on falls. The websites of health authorities were also checked. We searched also for information about safety policy and interventions.

Fisher's exact test was used to compare categorical data of two or more independent groups. A $p$ value of less than 0.05 was accepted as significant. Data were analyzed using Statistical Package for the Social Sciences (IBM-SPSS version 23.0, Chicago, Il, USA).

\section{Results}

Data from health authorities lacked details on personal and environmental risk factors and could not be studied. Newspaper clippings documented 96 fall incidents of children 0-15 years during the study period. After cleaning the data and excluding duplicate cases (3 cases), non-residential cases ( 1 at hotel, 1 at the airport, 1 at school) and intentional injuries (5 suicides; 3 homicides; 1 child was thrown from window during a fire by a mother), 81 cases were included in the final analysis. Fifty-three percent $(n=42)$ were boys and $4 \%(n=3 / 75)$ were UAE-nationals. Male to female ratio was $1: 1.1$. The mean (range) age was 4.9 years $(1-15)$ (Fig. 1, Table 1). Forty-nine percent $(n=39)$ were from the Emirate of Sharjah. Thirty-eight (47\%) children fell from windows, 36 (44\%) from balconies, and 7 (9\%) cases were unknown. Twenty-two (27\%) children climbed on the furniture placed on a balcony or close to a window.

Information about supervision was available in 43 cases (53\%). There was another person present in the apartment when the child fell in 25 cases (31\%) mother, father, or both parents in $18 / 25$ cases (72\%), grandmother or aunt in 2 cases, maid in 2 cases and older

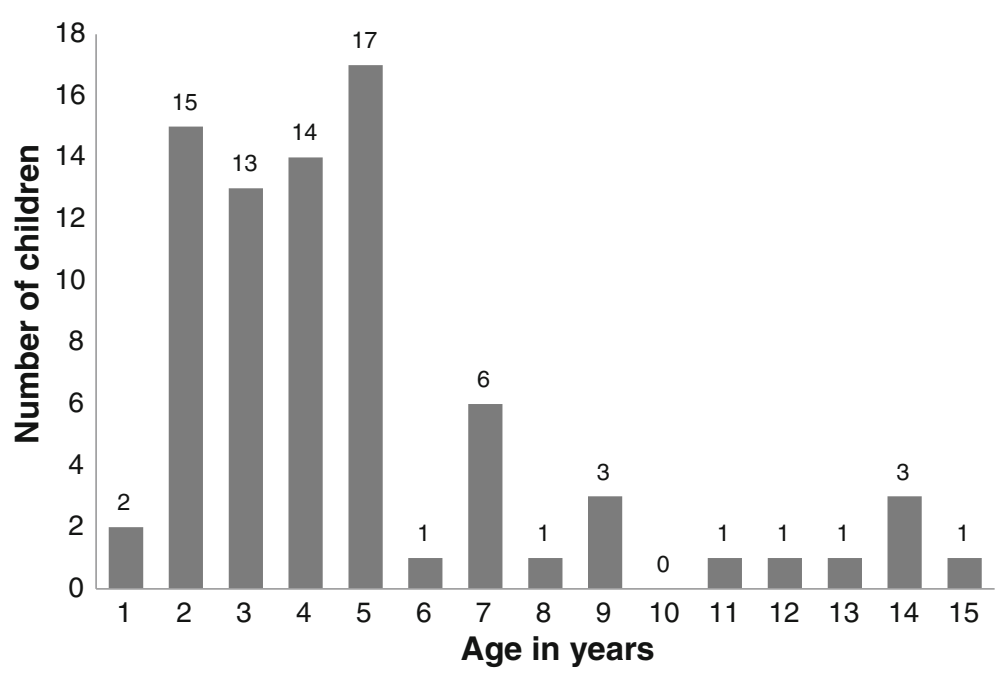

Fig. 1 Pediatric falls from windows/balconies by age $(n=81)$ 
Table 1 Demographic variables

\begin{tabular}{|c|c|c|c|}
\hline Variable & & $n$ & $\%$ \\
\hline \multicolumn{4}{|l|}{ Gender } \\
\hline & Male & 42 & 52.5 \\
\hline & Female & 38 & 47.5 \\
\hline \multicolumn{4}{|c|}{ Age group } \\
\hline & $0-5$ & 61 & 77.2 \\
\hline & $6-10$ & 11 & 13.9 \\
\hline & $11-15$ & 7 & 8.9 \\
\hline \multicolumn{4}{|c|}{ Nationality } \\
\hline & UAE & 3 & 4 \\
\hline & Asian & 24 & 32 \\
\hline & Other Arab & 40 & 53.3 \\
\hline & Other & 8 & 10.7 \\
\hline \multicolumn{4}{|l|}{ Emirate } \\
\hline & Sharjah & 39 & 48.7 \\
\hline & Abu Dhabi & 16 & 20 \\
\hline & Dubai & 10 & 12.5 \\
\hline & Ajman & 9 & 11.3 \\
\hline & Fujeirah & 4 & 5 \\
\hline & RAK & 2 & 2.5 \\
\hline \multicolumn{4}{|c|}{ Supervision } \\
\hline & Yes & 25 & 54.3 \\
\hline & No & 21 & 45.7 \\
\hline
\end{tabular}

UAE United Arab Emirates, RAK Ras Al Khaimah sibling in one case). Children were alone in 21 cases. One child was autistic.

Twenty-nine children fell from less than 5 floors (37\%), 33 from 5 to 10 floors (42\%), and 16 from more than 10 floors (21\%) (Fig. 2). Falls were more frequent in May $(n=12 ; 15 \%)$ (Fig. 3$)$, in the evening $(n=19$; $38 \%)$, and on Tuesday ( $n=14 ; 19 \%)$, (Fig. 4). Fortynine children died on spot (60\%), 11 children died in the hospital (13\%), and 15 (19\%) were hospitalized and survived the fall incident. The place of death was unknown in six children (7\%). 6/8 (75\%) children falling from 1 to 2 floors survived, 7 out of 26 (26.9\%) falling from 3 to 5 floors survived and 2/38 (5.3\%) falling from more than 5 floor survived $(p<0.001$, Fisher's Exact test). We identified local governmental efforts to introduce new building regulations and increase public awareness. Changes in regulations were usually triggered by fatal fall incidents.

\section{Discussion}

Children under 5 years old and those living in Sharjah Emirate were at high risk of falling from windows or balconies. Majority of those who fell from higher levels died. Many children were not alone in the apartments when they fell.

The male preponderance has been described in many studies [3, 9-11]. In contrast, our study showed a gender male/female ratio of $1: 1.1$. UAE-nationals were only $4 \%$ of all victims. UAE nationals usually live in villas having less number of floors with better supervision by maids. Similar to others, majority of our cases were children under 5 years of age $[3,9,12]$. Small actively moving children who love to explore things without appreciation

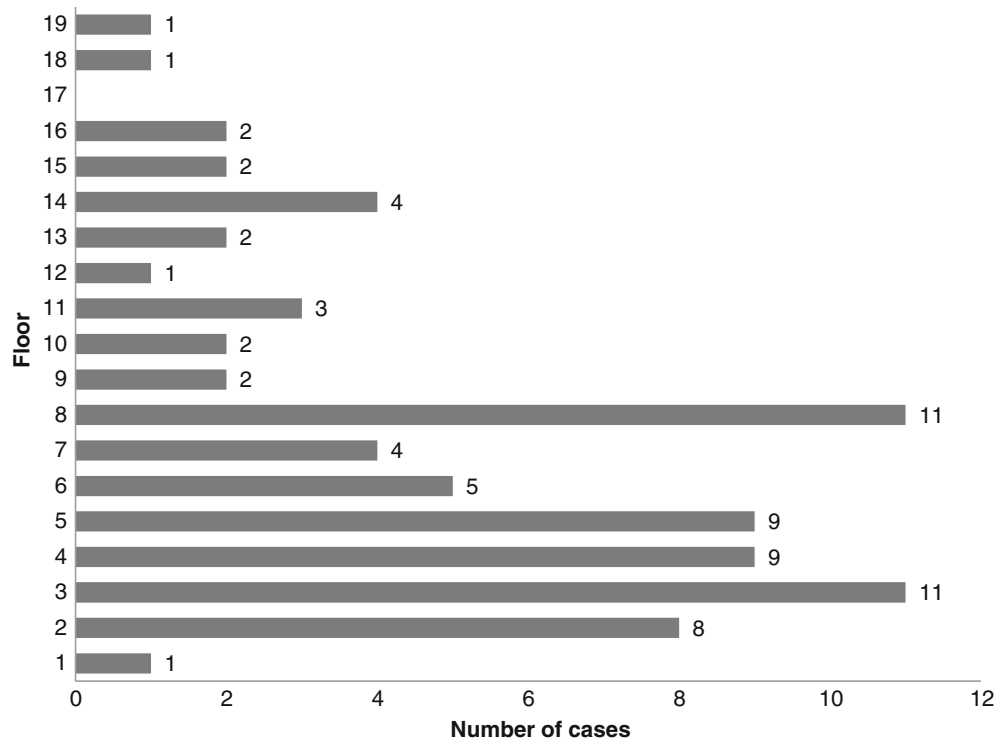

Fig. 2 Pediatric falls from windows/balconies by floor $(n=78 / 81)$ 

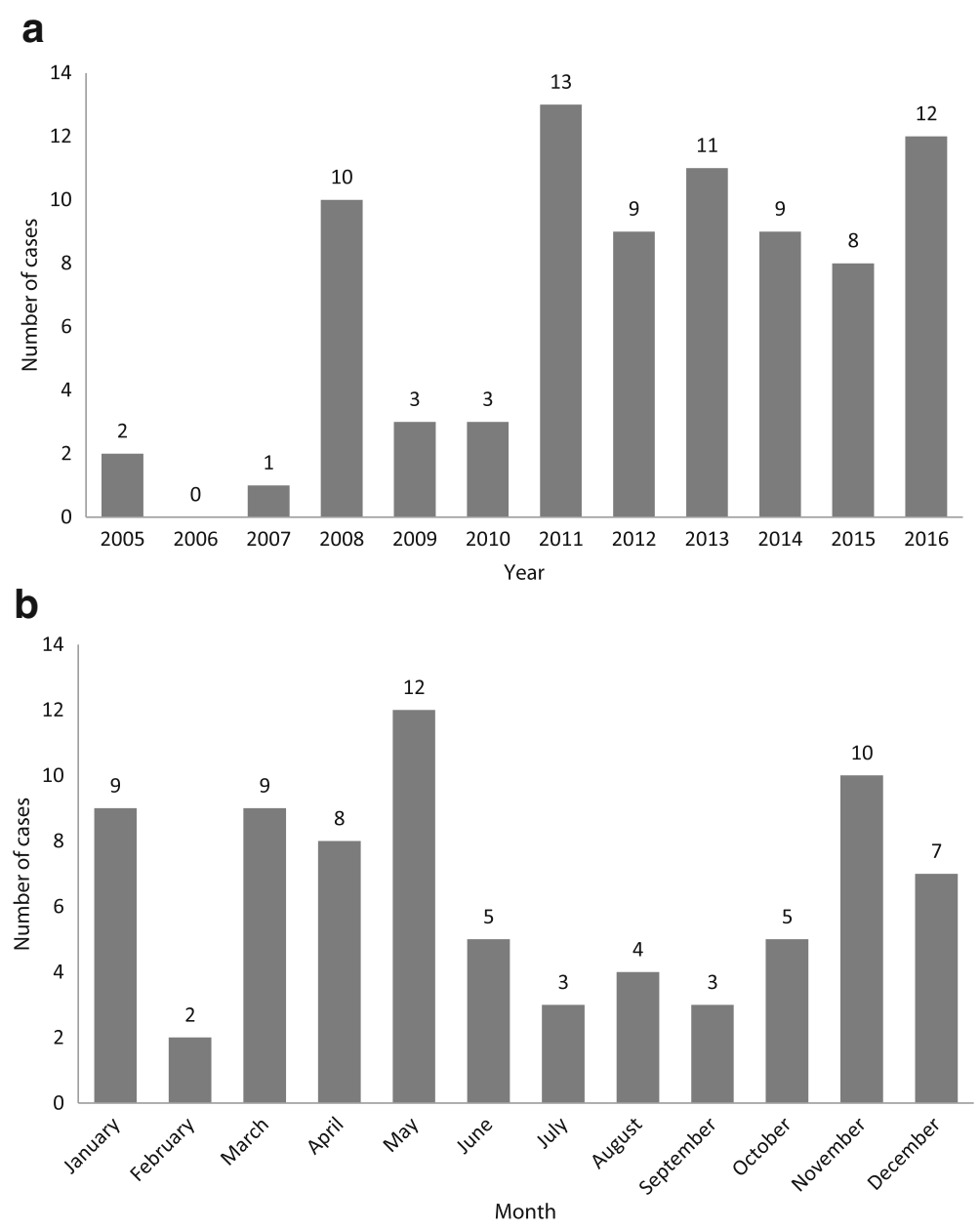

Fig. 3 Pediatric falls from windows/balconies by year (a) and month (b) $(n=77 / 81)$

of risks are more vulnerable to injuries [13]. A small body of a child can easily squeeze through small window gaps or railings of balconies.

The high incidence of falls in Sharjah Emirate can be explained by the high proportion of high buildings, and residents having low socio-economic status. If both parents are working and cannot afford to appoint a maid or if the mother is busy working at home, then there is lack of supervision of children.

Falls are more serious if they are from higher levels $[12,14,15]$. Children who fell from less than two floors in our study had a better chance to survive. Furthermore, kinetic energy absorbing surfaces, such as grass or vegetation may reduce the fall impact [15].

Fall incidents occurred more often in cooler months when there was no need to use air conditioning because families tend to open windows and balconies at that time. In other countries, there were more fall cases during the hot summer, especially among families with lowincome living in buildings without air-conditioning [3, 10, 16]. Less falls occurred during the summer in our study. The exceptionally hot weather in our setting discourages opening the windows because of the airconditioned environment. Furthermore, many families travel overseas for summer holidays.

More incidents occurred during the working days of the week and decreased during the weekends, possibly due to increased supervision by parents and older siblings. The time of incidents differs in the literature. Some studies showed more falls in the afternoon [3,5], while others in the evening [9].

The information about supervision in newspapers was limited. Nevertheless, many of the children were not alone during the incident similar to a US study, in which more than half the falls occurred when a parent was at home [3]. In another study from Switzerland, the supervising person did not see the fall of the child. The child was left alone at home or left unattended for a short period of time [11]. Parents, maids, or siblings may have difficulty to watch children all the time. They may be distracted by other activities. Many parents undermine the importance of limiting access of children to 


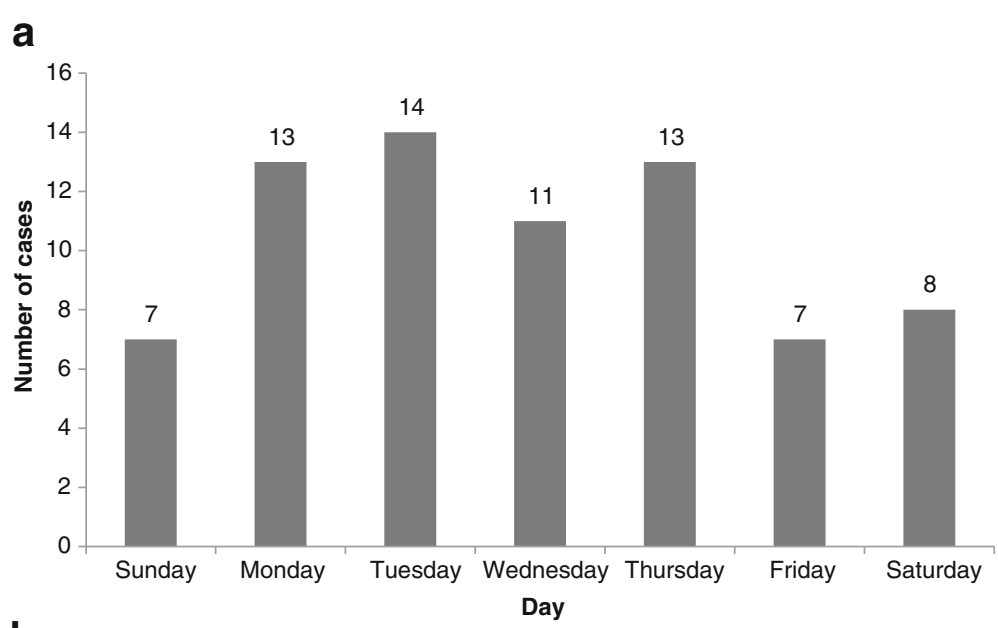

b

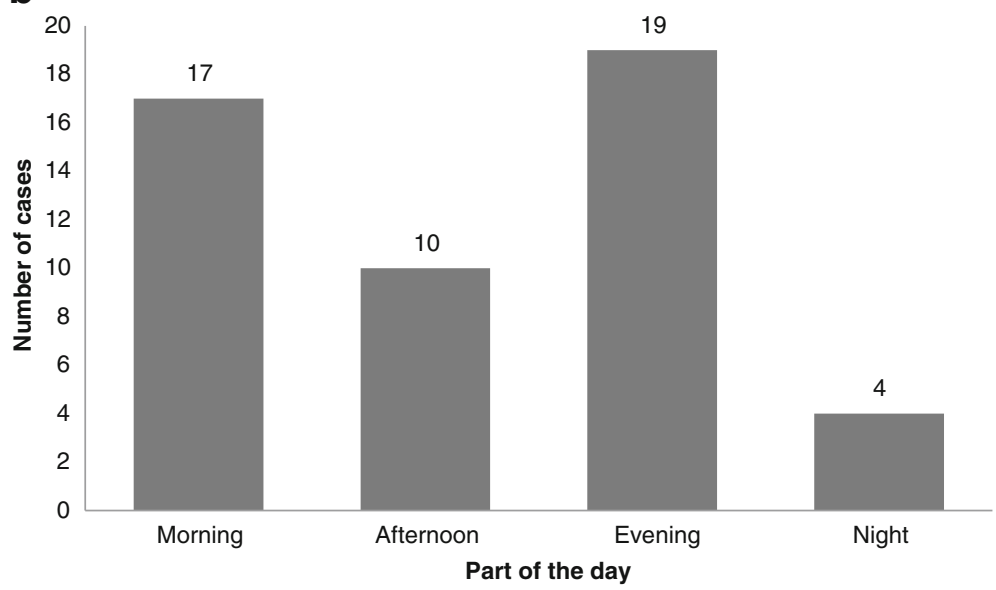

Fig. 4 Pediatric falls from windows/balconies by day of the week (a) and part of the day (b) $(n=77 / 81 ; 24 / 81)$

balconies or windows. One alarming case study occurred when police saved a child sitting at the kitchen window by breaking into the apartment. The police warned the parents. Nevertheless, the same child fell to death from the balcony later on [17].

Our data suggest that furniture placed near a window or at a balcony is a contributing risk factor for falls, because the child has an easier access to the window. This was reported by others $[3,11,16]$.

The government, municipalities, police, and building construction sectors in the UAE reacted to the fall incidents and have made active efforts to reduce the burden of falls over the last few years. This included introduction of new building and construction laws, enforcement of window guards, requiring minimum heights for railing at balconies, and educational campaigns. The challenge remains with the high turn-over of working expatriate families having different educational, cultural and socioeconomic background, and various languages. The broad base public education should not focus only on parents, but also on maids, building owners, and managers [15].

\section{Limitations of the study}

We have to acknowledge that there are certain limitations of our study. There is debate about the value of using newspaper clippings for injury prevention [18-20]. Despite that debate, we can observe the high precision of information on the floor level from which children fell and their associated mortality. We could not previously reach that level of accuracy in our prospectively collected data of a trauma registry [21]. We have previously studied charts of pediatric injured patients who fell from height and found that detailed information on risk factors was missing [22]. Furthermore, $60 \%$ of our cases in the present study died on scene having no hospital charts.

Available data reports on mortality and morbidity is usually lacking details on personal and environmental risk factors which can affect appropriate local prevention strategies. There is no unified health information system in the United Arab Emirates. Every health authority has its own injury data collection.

Although newspaper clippings contained rich information, some cases could have been missed, including less 
serious cases which may be treated in emergency rooms or hospitals. There is a possibility for selection bias by newspapers as they capture more serious conditions, while milder cases may have survived. Our study population represents only the tip of an iceberg. The exact time of incidents is lacking in our study. We could not also verify the reported information with official death reports. Although death reports in our setting improved by introducing an electronic reporting system, the access to data is limited. Some of our unintentional falls could be cases of child abuse or may include suicide attempts, especially among older children.

\section{Conclusions}

Newspaper clippings proved to be useful to study national pediatric falls from heights. It is necessary to improve window safety by installing window guards and raising awareness among parents, maids, and building owners and managers.

\section{Acknowledgements}

Not applicable.

\section{Availability of data and materials}

This study was supported by a SURE UAE University grant (No. 31 M225SURE 2015) and UPAR UAE University grant (No.31 M128).

\section{Availability of data and materials}

All data generated and analyzed during the current study are available at websites of newsletters.

\section{Authors' contributions}

MG did the newsletter search, analyzed data, drafted the manuscript, and approved the final version for submission. HMA, MRA, and NNA were working together on the newsletter search did partial data analysis, critically reviewed, and approved final version of manuscript for submissions. FMA helped in data analysis, drafted with MG the manuscript, and approved the final version for submission.

\section{Ethics approval and consent to participate}

Not applicable.

\section{Consent for publication}

Not applicable.

\section{Competing interests}

All authors declare that they have no competing interests.

\section{Publisher's Note}

Springer Nature remains neutral with regard to jurisdictional claims in published maps and institutional affiliations.

\section{Author details}

'Institute of Public Health, College of Medicine and Health Sciences, UAE University, Al-Ain, United Arab Emirates. ${ }^{2}$ Medical Student, College of Medicine and Health Sciences, UAE University, Al-Ain, United Arab Emirates. ${ }^{3}$ Department of Surgery, College of Medicine and Health Sciences, UAE University, Al-Ain, United Arab Emirates.
Received: 28 August 2017 Accepted: 4 October 2017

Published online: 16 October 2017

\section{References}

1. Scuffham P, Chaplin S, Legood R. Incidence and costs of unintentional falls in older people in the United Kingdom. J Epidemiol Community Health. 2003;57:740-4.

2. World Health Organization. WHO global report on falls prevention in older age. Geneva: World Health Organization; 2007.

3. Vish NL, Powell EC, Wiltsek D, Sheehan KM. Pediatric window falls: not just a problem for children in high rises. Inj Prev. 2005;11:300-3.

4. Author unknown. The book of accidents. New Haven: Designed for Young Children; 1830.

5. Spiegel CN, Lindaman FC. Children Can't fly: a program to prevent childhood morbidity and mortality from window falls. Am J Public Health. 1977;12:1143-7.

6. Barlow B, Niemirska M, Gandhi RP, Leblanc W. Ten years of experience with falls from height in children. J Pediatr Surg. 1983;18:509-11.

7. Central Intelligence Agency. The world Factbook 2017. https://www.cia.gov/ library/publications/the-world-factbook/geos/ae.html Accessed 6 June 2017.

8. Grivna M, Aw TC, El-Sadeg M, Loney T, Sharif A, Thomsen J, et al. The legal framework and initiatives for promoting safety in the United Arab Emirates. Int J Inj Control Saf Promot. 2012;19:278-89.

9. Istre GR, McCoy MA, Stowe M, Davies K, Zane D, Anderson RJ, et al. Childhood injuries due to falls from apartment balconies. Inj Prev. 2003;9: 349-52.

10. Pressley JC, Barlow B. Child and adolescent injury as a result of falls from buildings and structures. Inj Prev. 2005;11:267-73.

11. Mayer L, Meuli M, Lis U, Frey B. The silent epidemic of falls from buildings: analysis of risk factors. Pediatr Surg Int. 2006;22:743-8.

12. Freyne B, Doyle J, McNAmara R, Nicholson AJ. Epidemiology of high falls from windows in children. Ir Med J. 2014;2:57-9.

13. Melo JRT, Di Rocco F, Lemos-Junior LP, Roujeau T, Thelot B, Sainte-Rose C, et al. Defenestration in children younger than 6 years old: mortality predictors in severe head trauma. Childs Nerv Syst. 2009:25:1077-83.

14. Khambalia A, Joshi P, Brussoni M, Raina P, Morrngiello B, McArthur C. Risk factors for unintentional injuries due to falls in children aged $0-6$ years: a systematic review. Inj Prev. 2006;12:378-81.

15. American Academy of Pediatrics, Committee on Injury and Poison Prevention. Falls from heights: windows, roofs and balconies. Pediatrics. 2001;107:1188-91.

16. Hussain N, Mewasingh L, Gosalakkal J. Is the heat wave increasing the number of falls from open windows among children? Arch Dis Child. 2007:92:90

17. Gulf News. Parents of toddler who fell from building face jail. 2012. http:// gulfnews.com/news/uae/emergencies/parents-of-toddler-who-fell-frombuilding-face-jail-1.976534. Accessed 6 June 2017.

18. Barss P, Subait OM, Ali MHA, Grivna M. Drowning in a high-income developing country in the Middle East: newspapers as an essential resource for injury surveillance. J Sci Med Sport. 2009;12:164-170.

19. Baullinger J, Quan L, Bennett E, Cummings P, Williams K. Use of Washington state newspapers for submersion injury surveillance. Inj Prev. 2001;7:339-42.

20. Rainey DY, Runyan CW. Newspapers: a source for injury surveillance. Am J Public Health. 1992;82:745-6.

21. Grivna M, Hani OE, Abu-Zidan FM. Epidemiology, morbidity and mortality from fall-related injuries in the United Arab Emirates. Scand J Trauma Resusc Emerg Med. 2014:22:51.

22. Grivna M, Barss P, Stanculescu C, Hani OE, Abu-Zidan FM. Home and other nontraffic injuries among children and youth in a high-income middle eastern country: a trauma registry study. Asia Pac J Public Health. 2015;27: NP1707-18. 